\title{
Sudden infant death-dysgenesis of the testes syndrome
}

INSERM

\section{Source}

INSERM. (1999). Orphanet: an online rare disease and orphan drug data base. Sudden infant death-dysgenesis of the testes syndrome. ORPHA:168593

Sudden infant death with dysgenesis of the testes (SIDDT) syndrome is a lethal condition in infants with dysgenesis of testes. 